\title{
Delamination at Thick Ply Drops in Carbon and Glass Fiber Laminates Under Fatigue Loading
}

\author{
Daniel D. Samborsky ${ }^{*}$, Timothy J. Wilson†, Pancasatya Agastra ${ }^{\dagger}$ and John F, Mandell ${ }^{\star}$ \\ Department of Chemical and Biological Engineering, Montana State University, Bozeman, MT, 59717, USA
}

\begin{abstract}
Delamination at ply drops in composites with thickness tapering has been a concern in applications of carbon fibers. This study explored the resistance to delamination under fatigue loading of carbon and glass fiber prepreg laminates with the same resin system, containing various ply drop geometries, and using thicker plies typical of wind turbine blades. Applied stress and strain levels to produce significant delamination at ply drops have been determined, and the experimental results correlated through finite element and analytical models. Carbon fiber laminates with ply drops, while performing adequately under static loads, delaminated in fatigue at low maximum strain levels except for the thinnest ply drops. The lower elastic modulus of the glass fiber laminates resulted in much higher strains to produce delamination for equivalent ply drop geometries. The results indicate that ply drops for carbon fibers should be much thinner than those commonly used for glass fibers in wind turbine blades.
\end{abstract}

\section{Introduction}

The primary structural elements in most wind turbine blades are spars with tapering thickness along their length. Thickness tapering in laminated composites is accomplished by a series of terminations of individual plies or groups of plies, called ply drops. When loads are applied to a blade, these ply drops cause stress concentrations in adjoining plies and can also serve as an initiation site for the separation, or delamination, of the plies. ${ }^{1-9}$ Ply delamination, if widespread, can cause a general loss in structural integrity of the blade and has been cited as an underlying cause of

${ }^{*}$ Research Engineer, ${ }^{\dagger}$ Graduate Student, ${ }^{\ddagger}$ Professor 
blade failures. ${ }^{9}$ Delamination and ply drops have received extensive attention in the general composites literature ${ }^{1-5}$ and, to a lesser extent, in wind turbine blade technology. ${ }^{6,7}$ Methodologies for predicting delamination under static and fatigue loading using finite elements have been demonstrated. ${ }^{4,6}$ Recent attention has been given to this problem in the aerospace community in the area of tapered flex beams for helicopter rotors. ${ }^{8}$ While the fundamentals of delamination problems and ply drops have received widespread attention in the composites literature, for the wind turbine blade application the effects of thicker plies and lower cost processing, coupled with the very high-cycle fatigue environment, require a reexamination of their practical importance.

The ply drop problem is of particular concern for wind turbine blades using carbon fibers for three reasons: first, the more directional elastic constants of carbon fiber laminates often increase the tendency to delaminate relative to glass; second, to reduce cost, the plies are often thicker in composites for wind turbine blades relative to aerospace applications; and third, the ultimate and fatigue strains in compression for lower cost forms of carbon fiber laminates are lower than for glass, ${ }^{10,11}$ and may be design drivers in some cases. Thus, while ply drops have received limited attention in glass fiber blades, they may prove critical with carbon fibers.

The study reported here has concentrated on exploring the strain levels under fatigue loading for delamination and/or gross failure at ply drops with several variations, including carbon vs. glass fibers, ply drop location through the thickness, number of plies dropped at one location (simulating changes in ply thickness), overall laminate thickness, and loading conditions (tension, compression and reversed loading). While fracture mechanics based methodology is available to predict delamination growth under defined conditions, ${ }^{4,6}$ the most direct data for material selection and design of wind turbine blades are in the form of stress and strain levels to produce significant delamination, which can be used with traditional design and analysis methods. However, interpretation of the experimental results and extension to other cases is enhanced by an on-going finite element analysis of several of the cases, based on idealized geometries and interlaminar fracture mechanics. ${ }^{13}$

\section{Background}

This study was preceded by an exploratory study of carbon/glass hybrid laminates also processed by prepreg molding. ${ }^{10}$ The laminates contained $0^{\circ}$ carbon fiber plies and $\pm 45^{\circ}$ glass fiber plies, where $0^{\circ}$ is the uniaxial load direction. All tests were static compression. The position and number of ply drops and ply joints was varied; $0^{\circ}$ carbon ply thicknesses were about $0.30 \mathrm{~mm}$. 
The results of these tests showed potentially serious strength reductions for thick ply drops. Compression strength and ultimate compression strain were reduced moderately for a single ply drop or joint, to an ultimate compression strain of about $0.7 \%$ for the best ply drop geometries. Doubling the dropped thickness to $0.6 \mathrm{~mm}$ at the same position reduced the ultimate compressive strain values to 0.44 and $0.54 \%$ depending on ply drop position. Results were similar whether plies were dropped at mid-thickness of the $0^{\circ}$ ply stack or on the surface of the stack, under surfacing $\pm 45^{\circ}$ layers.

Failure modes for the ply drop coupons under static loading did not indicate any stable delamination growth prior to gross compressive failure. However, earlier studies ${ }^{6}$ of glass laminates had shown a shift to delamination prior to gross failure under fatigue loading. Because the delamination process is strictly a matrix/interface failure, it is more sensitive to fatigue loading compared with the outstanding fatigue resistance of carbon fiber laminates in fiber dominated directions. Thus, a failure mode shift to delamination could potentially cause a significant increase in slope of the S-N fatigue curve compared to coupons without ply drops; this concern provided the impetus for this fatigue study.

\section{Experimental Methods}

Materials. Three different prepregs supplied by Newport Adhesive and Composites were used in this study. Two were unidirectional prepregs, carbon (NCT307-D1-34-600-G300) and E-glass (NCT307- D1-E300), and one was E-glass 0/90 woven fabric (NB307-D1-7781-497A) orientated at $45^{\circ}$ for \pm 45 plies. All three prepregs employed the same epoxy resin system and had the same nominal ply thickness of $0.3 \mathrm{~mm}$. All laminates utilized external $\pm 45^{\circ}$ glass plies over a stack of $0^{\circ}$ plies with the exception of ply properties, which were determined with unidirectional specimens. Fabrication was by vacuum bag and curing was at $121^{\circ} \mathrm{C}$, described in more detail in References 12 and 13. Thin laminates $\left(<4 \mathrm{~mm}\right.$ thick) in the base configuration $\left( \pm 45 / 0_{9} / \pm 45\right)$ were used for exploratory tests under tensile, compressive, and reversed fatigue loading. Thicker laminates, $\left[( \pm 45)_{3} / 0_{27} /( \pm 45)_{3}\right](10-13 \mathrm{~mm}$ thick $)$ were used for the main study, subjected only to compressive loading. Additional $3 \mathrm{~mm}$ thick fiberglass G10 tabs were bonded to the test coupons with Hysol 9309.2 NA epoxy and cured for two hours at $60^{\circ} \mathrm{C}$.

Mechanical Testing and Data Reduction. Figure 1 gives specimen dimensions and photographs of typical test specimens. Mechanical testing was performed with Instron 8501 and 8802 servo-hydraulic test machines with 
capacities of 100 and $250 \mathrm{kN}$ respectively. Except for ply properties (Table 1) static (1-cycle) tests were performed under displacement control with a linear ramp rate of $13 \mathrm{~mm} / \mathrm{s}$, which produced a similar loading rate to the fatigue tests (Table 2). The fatigue tests were performed under load control with a sinusoidal waveform with frequencies between 1 and $6 \mathrm{~Hz}$ (varied approximately inversely with maximum load).

Compression test specimens of the control thin laminates with no ply drops used $25 \mathrm{~mm}$ wide rectangular specimens having a gage length of $13 \mathrm{~mm}$. Thick laminates $(10-13 \mathrm{~mm})$ and thin laminates with a ply drop used a $25 \mathrm{~mm}$ gage length. Tests were monitored for alignment and fracture mode to avoid elastic buckling. The hydraulic grips were fit with special anti-rotation and anti-deflection restraints ${ }^{12,14}$ needed on both testing machines, as they employ hydrostatic bearings which allow some lateral grip movement. Coupons for thick specimens were designed such that end loading was imposed by the grips in addition to shear loading from the grip faces; the relative amounts of end and shear loading was not determined. Finite element results described later confirmed the adequacy of the specimen length for most cases to avoid length effects on delamination growth. ${ }^{13}$

Compressive stress-strain curves were generated from specimens without ply drops to obtain modulus values used to calculate strains from the stress determined in the tests. All stresses and strains in the results represent the thin side of the ply drop specimens. Ply properties for each type of prepreg were obtained using standard test methods described in References 12 and 14.

Interply delamination resistance in pure Modes I and II $\left(\mathrm{G}_{\mathrm{IC}}\right.$ and $\left.\mathrm{G}_{\mathrm{IIC}}\right)$ used unidirectional $0^{\circ}$ double cantilever beam (DCB) and end notched flexure (ENF) test specimens. ${ }^{12}$ These specimens included a Teflon crack-starter strip embedded during fabrication as an initial crack. The $\mathrm{G}_{\mathrm{IC}}$ and $\mathrm{G}_{\mathrm{IIC}}$ values were determined from the initial crack growth from the starter strip, which provides the most conservative value for most wind turbine blade laminates. ${ }^{12}$

\section{Results and Discussion}

Thin Laminates. The thinner the laminate, the less complex are the test methodology and failure modes. However, thin laminates are not representative of thick blades in terms of the fraction of plies dropped at a particular cross-section. Thus, a series of relatively thin laminates, on the order of three to four millimeters thick, was tested both with and without ply drops under tensile, compressive, and reversed loading $(\mathrm{R}=0.1,10$, and -1.0 , where $\mathrm{R}$ is the ratio of minimum to maximum stress). The results were then compared with data for relatively thick laminates 
for selected geometries under compressive loading (which could take advantage of end loading to avoid grip failures). The ply configuration for the thin laminates was $\left( \pm 45 / 0_{9} / \pm 45\right)$, with additional plies added for half of the coupon length in the case of ply drops. As noted earlier, the $0^{\circ}$ plies contained carbon fibers, while the $\pm 45^{\circ}$ plies contained glass fibers $\left(0^{\circ}\right.$ is the uniaxial load direction $)$.

S-N fatigue curves for coupons without ply drops were reported in Reference 11 for this material system, for the similar ply configuration $\left( \pm 45 / 0_{8} / \pm 45\right)$ with the three R-values. Figures 2 and 3 from Reference 15 give the control tests with no ply drops, in terms of absolute maximum stresses and strains, respectively. Table 2 gives static strength and modulus values for these and other laminates. The tensile strength of fiberglass laminates is affected by the static testing rate, and the values in Table 2 would be on the order of $10-15 \%$ lower at standard test rates, while compressive strengths and carbon laminates would be much less affected. ${ }^{15}$ The compressive static strength and ultimate strain for the control laminate in Table 2 are higher than for the unidirectional material in Table 1 because of testing difficulties with the unidirectional material which are alleviated by the addition of \pm 45 surface plies in Table 2.

The results for the thin laminates containing double ply drops, $\left( \pm 45 / 0_{2}{ }^{*} / 0_{9} / 0_{2}{ }^{*} / \pm 45\right)$, where the $0_{2}{ }^{*}$ plies are dropped at mid-length, are given in Figures 4 and 5. The two double ply drops reduce the static strengths by approximately $45 \%$ in tension and $42 \%$ in compression (Table 2). These reductions for double ply drops are slightly less severe than those reported for a different prepreg system in Reference 10. However, as feared, the effects of ply drops on the fatigue life are significant, producing steeper S-N curves than for the controls (Figures 2 and 3). Failure is taken as the growth of a large (6 mm long) delamination from the ply drop location, or else simultaneous delamination and separation. Delamination is a matrix failure mode which follows a steeper S-N trend than do control laminates which are more fiber dominated. ${ }^{15}$ Maximum strain levels for $10^{6}$ cycles are below $0.3 \%$ for the laminates with double ply drops, compared with $0.6 \%$ to $1.0 \%$ for the control material, depending on R-value. As with the control material, reversed loading is most severe.

It is noteworthy that all three loading conditions produce delamination at the ply drop site in a similar strain range. Figure 6 is a photograph of a delamination crack growing from a ply drop with a typical pore at its tip; no significant difference could be determined between specimens with and without an obvious pore. The delamination in Figure 6 is a single crack separating the dropped plies and outside \pm 45 's from the remainder of the laminate. This pattern was observed for all coupons having ply drops at the outside of the 0 -stack, including the thick laminates, 
whereas interior ply drops often showed two cracks, one growing on each side of the dropped plies. Finite element results showed that for this geometry, delamination is dominated by the Mode II, or shear component, as discussed later. Mode II has a similar $\mathrm{G}_{\mathrm{II}}$ under tension and compression, but with the shear direction reversed, while reverse loading $(\mathrm{R}=-1)$ has twice the shear amplitude at the same maximum load, ${ }^{16}$ consistent with Figures 4 and 5 . Damage was also observed in the \pm 45 plies in the taper area which has been shown to affect the $\mathrm{G}$ values. ${ }^{13}$

Table 1. Ply Properties and Delamination Resistance in Material Principle Directions for E - Glass and Carbon Prepregs (static longitudinal, transverse, simulated shear and delamination resistance).

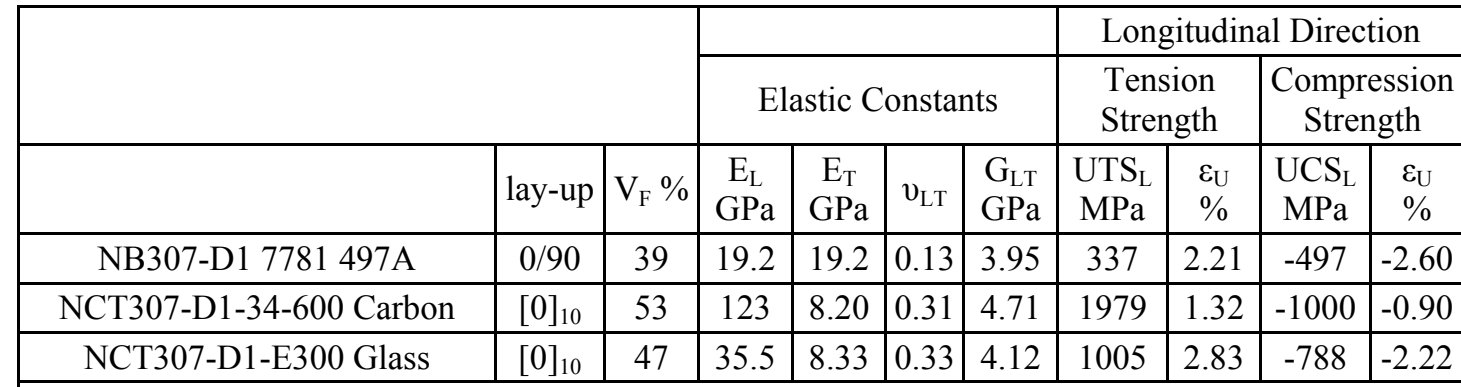

Notes: All coupons for this Table were tested at $0.25 \mathrm{~mm} / \mathrm{s}$, with a $100 \mathrm{~mm}$ gage length. Compression tests used a $13 \mathrm{~mm}$ gage length with unsupported edges. $\mathrm{E}_{\mathrm{L}}$ - Longitudinal modulus, $v_{\mathrm{LT}}$ - Poisson's ratio, $\mathrm{G}_{\mathrm{LT}}$ and $\tau_{\mathrm{TU}}$ - Shear modulus and ultimate shear stress by ASTM D3518. $\mathrm{UTS}_{\mathrm{L}}$ - Ultimate longitudinal tensile strength, $\varepsilon_{U}$ - Ultimate strain, $\mathrm{UCS}_{\mathrm{L}}$ - Ultimate longitudinal compressive strength.

\begin{tabular}{|c|c|c|c|c|c|c|c|}
\hline \multicolumn{2}{|c|}{} & \multirow{2}{*}{$\begin{array}{c}\text { Shear } \\
\text { Strength }\end{array}$} & \multicolumn{4}{|c|}{$\begin{array}{c}\text { Transverse Direction } \\
\text { Strength }\end{array}$} & \multicolumn{2}{c|}{$\begin{array}{c}\text { Compression } \\
\text { Strength }\end{array}$} \\
\cline { 5 - 9 } & lay-up & $\mathrm{V}_{\mathrm{F}} \%$ & $\begin{array}{c}\tau_{\mathrm{U}} \\
\mathrm{MPa}\end{array}$ & $\begin{array}{c}\mathrm{UTS}_{\mathrm{T}} \\
\mathrm{MPa}\end{array}$ & $\begin{array}{c}\varepsilon_{\mathrm{U}} \\
\%\end{array}$ & $\begin{array}{c}\mathrm{UCS}_{\mathrm{T}} \\
\mathrm{MPa}\end{array}$ & $\begin{array}{c}\varepsilon_{\mathrm{U}} \\
\%\end{array}$ \\
\hline NB307-D1 7781 497A & $0 / 90$ & 39 & 115 & 337 & 2.21 & -497 & -2.60 \\
\hline NCT307-D1-34-600 Carbon & {$[0]_{10}$} & 53 & 103 & 59.9 & 0.76 & -223 & -2.72 \\
\hline NCT307-D1-E300 Glass & {$[0]_{10}$} & 47 & 112 & 51.2 & 0.74 & -168 & -2.02 \\
\hline
\end{tabular}

\begin{tabular}{|c|c|c|c|c|}
\hline \multicolumn{5}{|c|}{ Delamination Resistance* } \\
\hline & Lay-up & $\mathrm{V}_{\mathrm{F}} \%$ & $\mathrm{G}_{\mathrm{IC}}\left(\mathrm{J} / \mathrm{m}^{2}\right)$ & $\mathrm{G}_{\mathrm{IIC}}\left(\mathrm{J} / \mathrm{m}^{2}\right)$ \\
\hline NCT307-D1-34-600 Carbon & {$[0]_{20}$} & 53 & $364(62)$ & $1829(87)$ \\
\hline NCT307-D1-E300 Glass & {$[0]_{20}$} & 47 & $365(37)$ & $2306(188)$ \\
\hline *13 to 14 tests, Brackets indicate standard deviation. \\
\hline
\end{tabular}


Table 2. Static Properties of Laminates With and Without Ply Drops

\begin{tabular}{|c|c|c|c|c|c|c|}
\hline Lay-up & $0^{\mathrm{O}}$ & $\begin{array}{c}\text { Ultimate } \\
\text { Compressive } \\
\text { Strength, } \\
\mathrm{MPa} \\
\end{array}$ & $\begin{array}{c}\text { Ultimate } \\
\text { Compressive } \\
\text { Strain, } \%\end{array}$ & $\begin{array}{c}\text { Ultimate } \\
\text { Tensile } \\
\text { Strength, } \\
\mathrm{MPa} \\
\end{array}$ & $\begin{array}{l}\text { Ultimate } \\
\text { Tensile } \\
\text { Strain, \% }\end{array}$ & $\begin{array}{c}\text { Tensile } \\
\text { Elastic } \\
\text { Modulus } \\
\text { GPa } \\
\end{array}$ \\
\hline$\left( \pm 45 / 0_{8} / \pm 45\right)$ & $\mathrm{C}$ & -1070 & -1.04 & 1496 & 1.40 & 101 \\
\hline$\left( \pm 45 / 0_{2} * / 0_{9} / 0_{2} * / \pm 45\right)$ & $\mathrm{C}$ & -617 & -0.64 & 827 & 0.85 & 96.3 \\
\hline$\left(( \pm 45)_{3} / 0 * / 0_{27} / 0 * /( \pm 45)_{3}\right)$ & $\mathrm{C}$ & -754 & -0.78 & ---- & ---- & 96.0 \\
\hline$\left(( \pm 45)_{3} / 0_{2} * / 0_{27} / 0_{2} * /( \pm 45)_{3}\right)$ & $\mathrm{C}$ & -642 & -0.67 & ---- & $\begin{array}{cl}--- \\
\end{array}$ & 94.3 \\
\hline$\left(( \pm 45)_{3} / 0_{4} * / 0_{27} / 0_{4} * /( \pm 45)_{3}\right)$ & $\mathrm{C}$ & -612 & -0.64 & ---- & ---- & 94.2 \\
\hline$\left(( \pm 45)_{3} / 0_{9} / 0_{2} * / 0_{9} / 0_{2} * / 0_{9} /( \pm 45)_{3}\right)$ & $\mathrm{C}$ & -549 & -0.57 & ---- & ---- & 95.3 \\
\hline$\left(( \pm 45)_{3} / 0 * / 0_{27} / 0 * /( \pm 45)_{3}\right)$ & $\mathrm{G}$ & -509 & -1.74 & 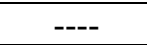 & $\begin{array}{c}--- \\
\end{array}$ & 29.4 \\
\hline$\left( \pm 45 / 0_{2} * / 0_{27} / 0_{2} * / \pm 45\right)$ & G & -470 & -1.61 & ---- & $\begin{array}{ll}--- \\
\end{array}$ & 28.8 \\
\hline$\left(( \pm 45)_{3} / 0_{4} * / 0_{27} / 0_{4} * /( \pm 45)_{3}\right)$ & $\mathrm{G}$ & -568 & -1.93 & ---- & ---- & 29.1 \\
\hline$\left(( \pm 45)_{3} / 0_{9} / 0_{2} * / 0_{9} / 0_{2} * / 0_{9} /( \pm 45)_{3}\right)$ & $\mathrm{G}$ & -488 & -1.67 & $\begin{array}{ll}--- \\
\end{array}$ & $\begin{array}{ll}--- \\
\end{array}$ & 29.4 \\
\hline
\end{tabular}

Thick Laminates. The thin laminate results indicate a serious problem with delamination at ply drops in laminates with carbon fiber $0^{\circ}$ plies. To better represent actual blade laminates while remaining within the load limits of available testing machines $(250 \mathrm{kN})$, a series of thicker laminates were tested under compression loads only. The number of plies dropped at the same location was varied to simulate unidirectional plies of varying thickness. The laminates are based on the configuration $\left[( \pm 45)_{3} / 0_{27} /( \pm 45)_{3}\right]$ with additional dropped $0^{\circ}$ plies running half of the coupon length, designated $0^{*}$. The $\pm 45^{\circ}$ plies are glass/epoxy while the $0^{\circ}$ plies are carbon/epoxy; the next section compares these laminates with all glass laminates having the same configuration and resin.

Figures 7 and 8 give the results for the laminates with varying numbers of plies dropped under the surface \pm 45 glass plies, $\left[( \pm 45)_{3} / 0_{\mathrm{n}} * / 0_{27} / 0_{\mathrm{n}} * /( \pm 45)_{3}\right]$, where $\mathrm{n}$ is 1,2 or 4 . Figure 9 compares the results from the thinner laminates with the thick laminates for the double ply drop case. As expected, the trends in Figure 7 show lower cycles to delaminate and lower static strength as the number of dropped plies at a location increases. The thick laminate with double ply drops delaminates at about the same strains as do the thin laminates with double ply drops (Figure 9). Thus, little effect of the fraction of $0^{\circ}$ plies dropped or total laminate thickness are evident, indicating that the data might also be representative of still thicker laminates typical of blade spar-caps, and that the $\mathrm{R}=0.1$ and -1.0 data obtained for the thin laminates might also be meaningful for the thick laminates. The dominant parameter in Figures 7 and 9 is the thickness of dropped material. Dropping four plies on each surface did not result in as great a reduction in lifetime as expected relative to dropping two plies; the reason for this is unclear, but a similar effect was 
seen with glass (Figure 11). It is possible that the gage length in this extreme case was too short to fully develop stress transfer into the drop area.

The double ply drop data, with a total thickness of $0.6 \mathrm{~mm}$ of dropped material, show a major decrease in fatigue strains relative to the control material having no ply drops for the carbon/epoxy $0^{\circ}$ plies. The limited test data for single ply drops show much improved performance over the double ply drops. Data for single ply drops were difficult to obtain because the load levels for delamination in fatigue were sufficiently close to the ultimate strength that failures often occurred in the grips prior to delamination at the ply drop. Taking the data as lower limits to the delamination lifetime, the performance with single ply drops $(0.3 \mathrm{~mm}$ dropped thickness $)$ appear much less problematic to potential blade performance than do the double ply drops. The single ply drop results in Figure 7 can be compared to literature data for hybrid glass/carbon flexbeams, where single ply drops half as thick as those used here produced delamination at surface strains on the order of $0.5 \%$ at $10^{6}$ cycles. ${ }^{5}$ Thus, the flexbeam data are consistent with the results of this study for a resin system with similar interlaminar toughness.

Earlier work found only slight effects of the position of the dropped plies through the thickness on static strength. ${ }^{6,10}$ The effect of dropping $0^{\circ}$ plies on the surface of the $0^{\circ}$ stack versus the interior is evident in Figure 10 for double ply drops. The double interior drops appear to perform slightly better than do the double surface drops at higher cycles. While the surface drops eliminate the carbon ply misorientation above the drop, cracking in the \pm 45 plies causes a situation where only a single interface must delaminate to unload the dropped plies (Figure 6), as discussed later. On the other hand, finite element results show a high opening mode $\mathrm{G}_{\mathrm{I}}$ for the interior ply drop geometry in compression, which has an as yet undetermined effect. ${ }^{13}$

Glass versus Carbon Fibers. To provide a direct comparison to all glass fiber laminates, the thick laminate configurations for carbon were also tested with glass fiber $0^{\circ}$ plies, using the same epoxy resin prepreg. The fiber volume fraction for the glass prepreg was lower than for carbon, 0.47 versus 0.53 . As noted earlier (Table 1), the static Mode II delamination resistance was somewhat higher for the glass, possibly due to the lower fiber content, which provides thicker resin areas and can produce higher toughness. ${ }^{17}$

The glass results given in Figure 11 indicate much higher strains to cause delamination for the glass $0^{\circ}$ plies as compared with the carbon (Figure 7) for all cycles and numbers of plies dropped. The relatively high static strength for the four ply drop case may, in addition to the earlier discussion, reflect an increased buckling resistance provided 
by the added thickness. Buckling effects are more pronounced with the lower modulus glass in compression. Even with four $0^{\circ}$ glass plies dropped at the same location (the surface of the $0^{\circ}$ ply stack), the strains to delaminate are similar to those for a single carbon ply drop. The comparison of glass and carbon is reversed when stress is considered, Figure 12 vs. Figure 8, due to the much higher carbon modulus (Table 2).

Figures 13 and 14 compare laminates with carbon and glass $0^{\circ}$ plies for the double internal ply drop case and the double external ply drop case, respectively. The former has a less complex delamination pattern than the ply drops at the surface of the $0^{\circ}$ stack, which have adjacent, often damaged, $\pm 45^{\circ}$ layers. In both cases the strains for delamination are much higher for the glass $0^{\circ}$ plies.

Discussion. These results indicate that delamination at ply drops under fatigue loading can occur at relatively low applied strain levels compared with in-plane failure, particularly for carbon fiber laminates. Comparison between Figures 2, 4 and 7 suggests that ply drop delamination would precede in-plane failure for all cycles and loading conditions for $0.3 \mathrm{~mm}$ or greater thickness ply drops with carbon $0^{\circ}$ plies. This thickness might not be a design driver for carbon because the in-plane fatigue resistance is very high. ${ }^{15}$ However, strain levels for delamination appear low enough to be significant in blade design for $0.6 \mathrm{~mm}$ or greater dropped thicknesses. The corresponding thickness for glass $0^{\circ}$ plies from Figure 11 and literature in-plane data for all fiberglass laminates, where delamination would precede in-plane failure (epoxy resin, about $50 \%$ fiber by volume), is about $0.6 \mathrm{~mm}$ in compression and between $0.6 \mathrm{~mm}$ and $1.2 \mathrm{~mm}$ in tension depending on the construction of the glass laminate (fabric style, etc.). ${ }^{13,15}$ (Fiberglass laminates are notably fatigue sensitive under tensile in-plane loading. ${ }^{15}$ ) As noted above, delamination at ply drops in glass fiber wind turbine blades has not been widely reported, but has been cited as a factor in a blade failure study. ${ }^{9}$ While most prepreg ply thicknesses are $0.3 \mathrm{~mm}$ or below, infused fabric ply thicknesses are often $1.0 \mathrm{~mm}$ or more, so ply drop design should be carefully considered even for fiberglass.

Delamination for these laminates and ply drop geometries has been modeled using finite element analysis (FEA) and approximate strength of materials relationships. Only the static strain energy release rates are obtained to assist in interpretation of the results. Full lifetime prediction would require a fatigue crack growth simulation as in Reference 18 . The results will be briefly summarized here, but are reported in detail by Wilson ${ }^{13}$ (available on www.coe.montana.edu/composites/). The nature of the delamination problem at ply drops is evident in Figures 1517 for the internal ply drop geometry reported experimentally in Figures 10, 13 and 14. Figures 16 and 17 represent the strain energy release rates at the delamination crack tips in terms of the opening mode, $\mathrm{G}_{\mathrm{I}}$, forward shearing 
mode, $G_{I I}$, and the sum of these, the total $G$. In tension the opening mode, $G_{I}$, is insignificant, and $G_{I I}$ is dominant (Figure 16). Figure 16 compares the forward shear, $\mathrm{G}_{\mathrm{II}}$, values for glass and carbon $0^{\circ}$ plies as a function of crack length at a thin side far-field static strain of $0.5 \%$. (The model assumes equal crack lengths, which was not generally observed experimentally, and the results are given for the total of the G-values at each crack tip. ${ }^{13}$ ) The results in Figure 16 help explain the various experimental observations, where carbon was much more prone to delamination than glass; the $\mathrm{G}_{\mathrm{II}}$ values driving crack growth are over three times as high for carbon as for glass at the same farfield strain. Compared to the critical Mode II $\mathrm{G}_{\mathrm{IIc}}$ values in Table 1, the carbon is at about half the critical value of $1829 \mathrm{~J} / \mathrm{m}^{2}$, while the glass is much lower. While the finite element results are for static loads, the values are consistent with the fatigue curves in Figure 13 at the same strain level of $0.5 \%$.

The tension case is a relatively simple example due to the low $\mathrm{G}_{\mathrm{I}}$ values for crack growth into the thicker side of the ply drop; this growth direction was observed for all experiments in this study. (Delamination in tension on the thin side, due to Mode I, has been observed in other recent cases having increased resistance to thick side delamination.) Figure 17 gives results for compression loading of the same geometry, at the same absolute applied strain. Now, both $G_{I}$ and $G_{I I}$ are of the same order of magnitude, and a mixed mode failure criterion is required, which complicates the problem. ${ }^{13}$ The surface ply drop geometry used in most of the experiments shows very low $\mathrm{G}_{\mathrm{I}}$ values in both tension and compression, and is, therefore, $\mathrm{G}_{\mathrm{II}}$ dominated for the single crack as shown in Figure $6 .{ }^{13}$ The consistency of the tension and compression data in Figure 4 is expected from the Mode II domination.

Delamination under Mode II domination can be approximately modeled using strength of materials assumptions including the absence of stress gradient and bending effects. These models are based on release of the strain energy in the delaminating plies as they unload. Ignoring effects of the \pm 45 plies, a solution by Ramkumar and Whitcomb ${ }^{19}$ can be rearranged to:

$$
G=\frac{\sigma^{2} t_{p}}{2 E_{L}}\left(\frac{t_{T}}{t_{T}-t_{p}}\right)=\frac{E_{L} \varepsilon^{2} t_{p}}{2}\left(\frac{t_{T}}{t_{T}-t_{p}}\right)
$$

where $\sigma$ is the applied stress, $\varepsilon$ the applied strain, $\mathrm{t}_{\mathrm{p}}$ the thickness of the dropped material, $\mathrm{t}_{\mathrm{T}}$ the total thickness and G the total strain energy release rate. Substituting for the geometry in Figure 15 (using the thick side strains of $0.45 \%$ for carbon and $0.44 \%$ for glass), the predicted G-values are $921 \mathrm{~J} / \mathrm{m}^{2}$ for carbon and $237 \mathrm{~J} / \mathrm{m}^{2}$ for glass. These are in good agreement with the $G_{\text {II }}$ values in Figure 16. However, this type of model cannot separate $G_{I}$ and $G_{I I}$ values for cases like Figure 17, and does not accurately predict many cases with significant $\mathrm{G}_{\mathrm{I}}$ values. ${ }^{13}$ 
The predictions based on Eq. (1) again demonstrate that the difference between carbon and glass derives primarily from the modulus, in this case $E_{L}$ of the dropped plies. $G$ in Eq. (1) is also proportional to $t_{p}$, the thickness of dropped material, for relatively thick laminates. For the same applied strain, $\varepsilon$, the ply stress is higher for the carbon than for glass by the ratio of their longitudinal moduli $\mathrm{E}_{\mathrm{C}} / \mathrm{E}_{\mathrm{G}}$, about 3.5 times for the prepregs used here (Table 1); at the same strain, the strain energy available in the dropped plies would differ by the same ratio. Thus, from Equation (1), the $\mathrm{G}$ value driving ply delamination will be about 3.5 times higher for the carbon fibers than for the glass fibers, for the same dropped thickness and applied strain. For the same applied stress, $\sigma$, the value of $\mathrm{G}$ would be about 3.5 times higher for glass due to the lower elastic modulus. The differences in E and G would be expected from Eq. (1) to result in predictable differences in applied strain to produce the same strain energy release rates, and expected fatigue crack growth rates. ${ }^{18}$ These differences would translate into about $(3.5)^{1 / 2}$ or 1.9 times higher strain for the same delamination lifetime for glass, or about 1.9 times higher stress for carbon. The data in Figures 13 and 14 are for the interior and exterior ply drops in compression. As noted above, the $\mathrm{G}_{\mathrm{I}}$ component is high for the interior case (Figure 17), but low for the exterior case. The experimental strain values at the same lifetime for the glass are almost three times higher than for carbon in Figure 13, with a slightly reduced ratio for the external case in Figure 14. The reason that the glass exceeds the predicted 1.9 times higher strain for the same lifetime compared with carbon may relate to the slightly higher $\mathrm{G}_{\text {IIc }}$ for glass in Table 1 and the mode mixity present for the internal case (Figure 17).

However, agreement with experimental data is good considering the approximate nature of the model geometries and the static loading discussed earlier.

\section{Conclusions}

The experimental results of this study indicate that ply drops in laminates can lead to delamination at relatively low applied strains under fatigue loading, particularly for carbon fibers. Results were generally similar for various loading conditions including tension, compression and reversed loading and, in compression, for relatively thin and thick laminates; however, other cases such as interior ply drops in tension show different delamination mode mixity in finite element modeling, and may perform differently. Delamination at ply drops in carbon occurs at lower strains than does in-plane fatigue failure in control laminates, for ply drops of $0.3 \mathrm{~mm}$ or greater thickness. The corresponding ply drop thickness for fiberglass is about 0.6 to $1.0 \mathrm{~mm}$ for tensile fatigue, depending on the fabric structure. Thus, delamination is likely to be a significant factor in blade fatigue performance for all practical carbon 
ply thicknesses, and for typical infusion fabric ply thicknesses with glass. The experimental results are correlated through finite element and strength of materials models.

\section{Acknowledgements}

This work was funded by Sandia National Laboratories under subcontract Z3609. Materials were supplied by Newport Adhesives and Composites, Inc. through Mr. Fred Saremi.

\section{References}

${ }^{1}$ Grimes, G.C. and Dusablon, E.G., Composite Materials: Testing and Design (Sixth Conference), ASTM STP 787, I.M. Daniel Ed., American Society for Testing and Materials, Philadelphia, 1982, pp. 513-538.

${ }^{2}$ Trethewey, B.R., Gillespie, J.W., Jr. and Wilkins., Proceedings of the American Society for Composites, Fifth Technical Conference, June 11-14, 1990, p. 361.

${ }^{3}$ Ochoa, O.O., and Chan, W.S., Proceedings of the American Society for Composites, Third Technical Conference, September 25-29, 1988, p. 633 .

${ }^{4}$ Buchholz, F. G., Rikards, R., and Wang, H., International Journal of Fracture,86:37-57, 1997.

${ }^{5}$ Murri, G.B., Salpekar, S.A., and O'Brien, T.K., Composite Materials: Fatigue and Fracture (Third Volume), ASTM STP 1110, T.K. O'Brian, Ed., American Society for Testing and Materials, Philadelphia, 1991, pp. 312-339.

${ }^{6}$ Cairns, D.S., Mandell, J.F., Scott, M.E., Maccagnano, J.Z., 1997 ASME Wind Energy Symposium, ASME/AIAA, AIAA-970953, pp. 197 - 208. (1997).

${ }^{7}$ Mandell, J.F., Cairns, D.S., Samborsky, D.D., Morehead, R.B., and Haugen, D.J., Journal of Solar Energy Engineering, ASME, Vol. 125, No. 4, pp. 522-530. November 2003. (2003).

${ }^{8}$ Murri, G.B., Schaff, J.R., Dobyns, A.L.," Fatigue Life Analysis of Hybrid Composite Tapered Flexbeams," NASA LaRC Technical Library Digital Repository http://hdl.handle.net/2002/15079

${ }^{9}$ Musial, W., Berry, D., Mandell, J., Ashwill, T., and Hartman, D., “Advances in Blade Design and Material Technology," Windpower 2005, American Wind Energy Association, 2005.

${ }^{10}$ Avery, D. P., Samborsky D. D., Mandell, J. F. and Cairns, D. S., 2004 ASME Wind Energy Symposium, ASME/AIAA., AIAA-2004-0174, pp. 54-63, (2004)

${ }^{11}$ Mandell, J.F., Samborsky, D.D., Wang, L., and Wahl, N.K., Journal of Solar Energy Engineering, ASME, Vol. 125, No. 4, pp. 506-514. November 2003.

${ }^{12}$ Mandell, J.F., Samborsky, D.D., and Cairns, D.S. "Fatigue of Composite Materials and Substructures for Wind Turbine 
Blades," Contractor Report SAND2002-0771, Sandia National Laboratories, Albuquerque, NM (2002).

${ }^{13}$ Wilson, T. J. "Modeling of In-Plane and Interlaminar Fatigue Behavior of Glass and Carbon Fiber Composite Materials,” M.S. Thesis, Mechanical Engineering, Montana State University (2006).

${ }^{14}$ Mandell, J. F. and Samborsky, D. D., "DOE/MSU Composite Material Fatigue Database: Test Methods, Materials, and Analysis,” Contractor Report SAND97-3002, Sandia National Laboratories, Albuquerque, NM (1997).

${ }^{15}$ Samborsky, D. D., Wilson, T. J., and Mandell, J. F. “Comparison of Tensile Fatigue Resistance and Constant Life Diagrams for Several Potential Wind Turbine Blade Materials,” 2007 ASME Wind Energy Symposium, ASME/AIAA, Reno, NV(2007).

${ }^{16}$ Tanaka, K., and Tanaka, H., Composite Materials: Fatigue and Fracture (Sixth Volume), ASTM STP 1285, $\quad$ E.A. Armanios, Ed., ASTM, 1997, pp. 126-142.

${ }^{17}$ Hunston, D.L., Moulton, R.J., Johnson, N.J., and Bascom, W.D., Toughened Composites, ASTM STP 937, Norman J. Johnson, Ed., American Society for Testing and Materials, Philadelphia, 1987, pp. 74-94.

${ }^{18}$ Krugar, R., and Konig, M., Composite Materials: Fatigue and Fracture, ASTM STP 1285, E. A. Armanios, Ed., American Society for Testing and Materials, Philadelphia (1997) pp.162-178.

${ }^{19}$ Ramkumar, R. L. and Whitcomb, J. D., Delamination and Debonding of Materials, ASTM STP 876, W. S. Johnson, ed., American Society for Testing and Materials, Philadelphia (1985). 

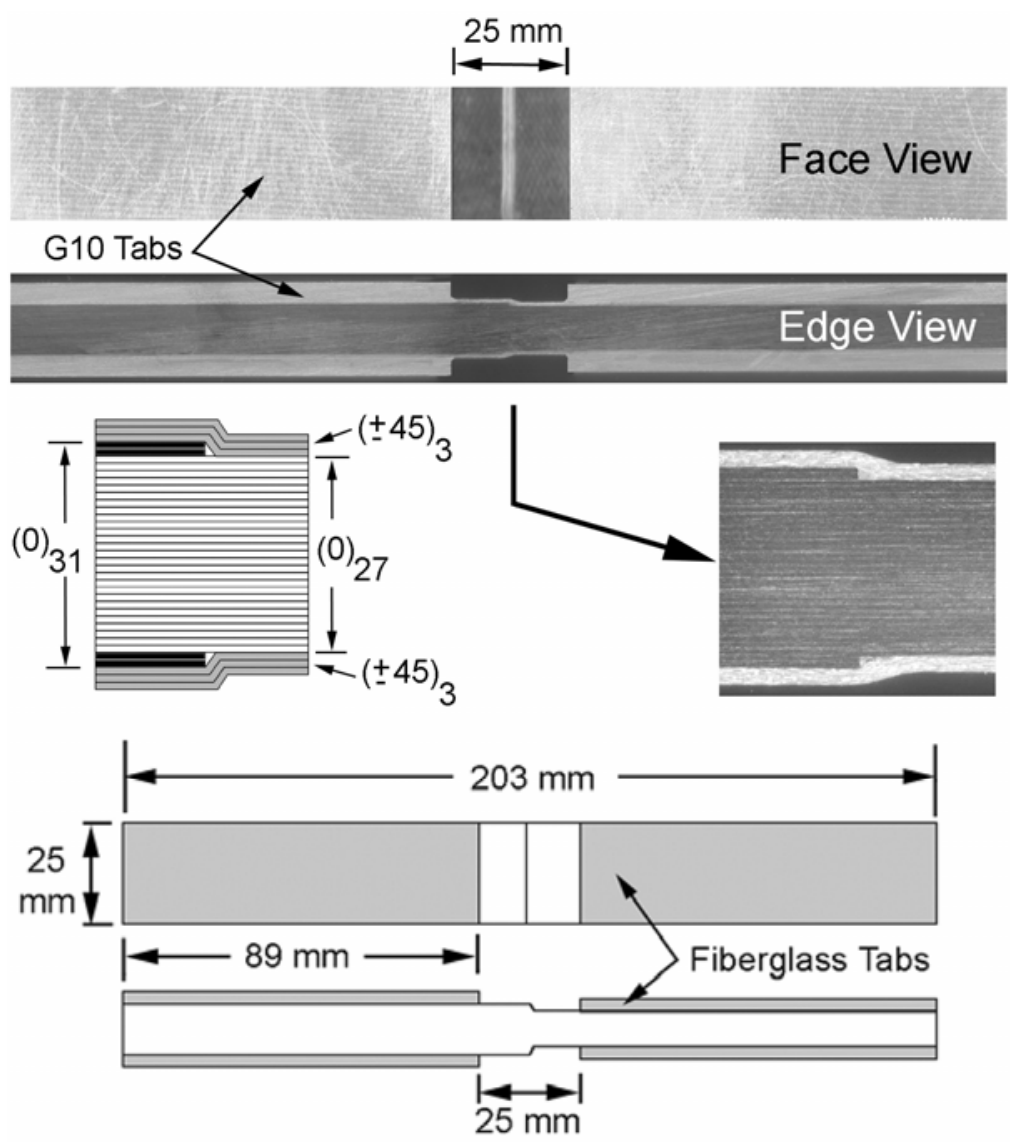

Figure 1. Schematic and Photograph of Typical Ply Drop Coupon (Two Plies Dropped at Surface of $0^{\circ}$ Stack).

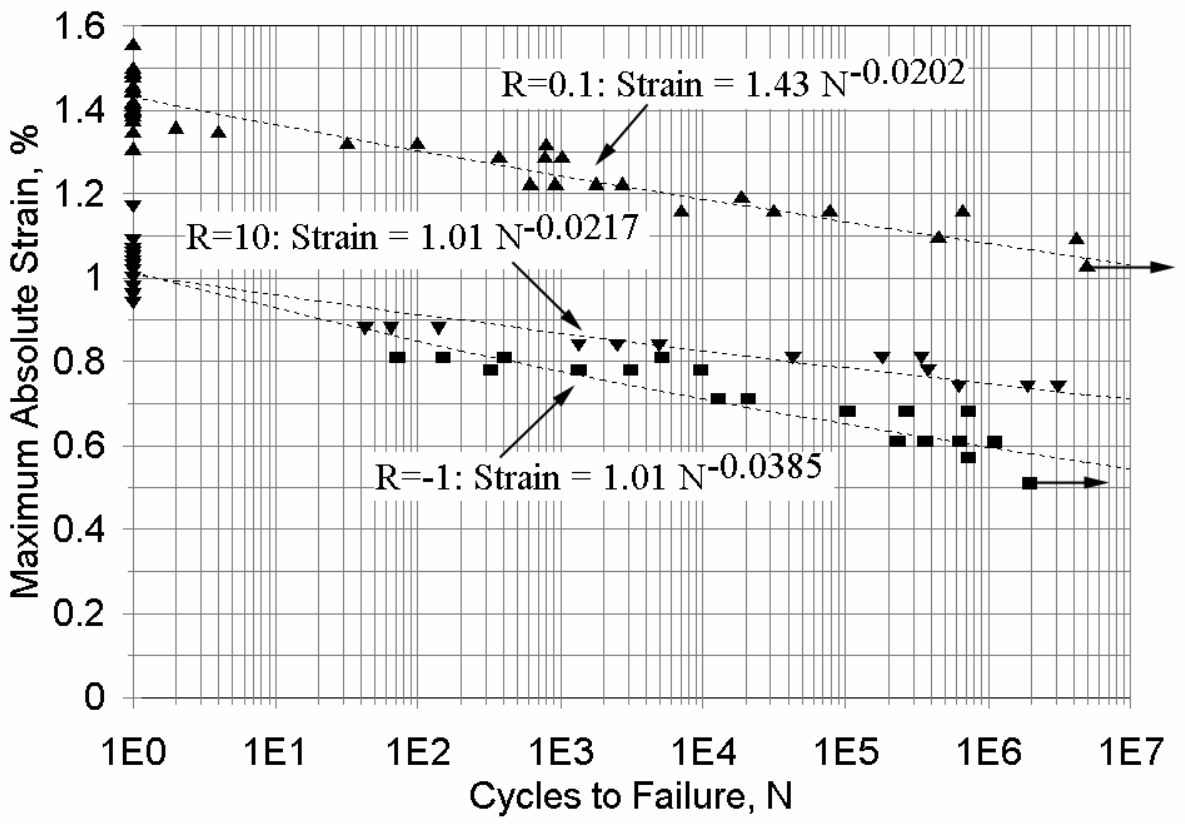

Figure 2. Maximum Absolute Strain to Failure Fatigue Data for $\left[ \pm 45 / 0_{8} / \pm 45\right]$ Control Laminate, $R=0.1,10$ and -1 (No Ply Drops; $0^{\circ}$ plies are carbon, $\pm 45^{\circ}$ plies are glass). 


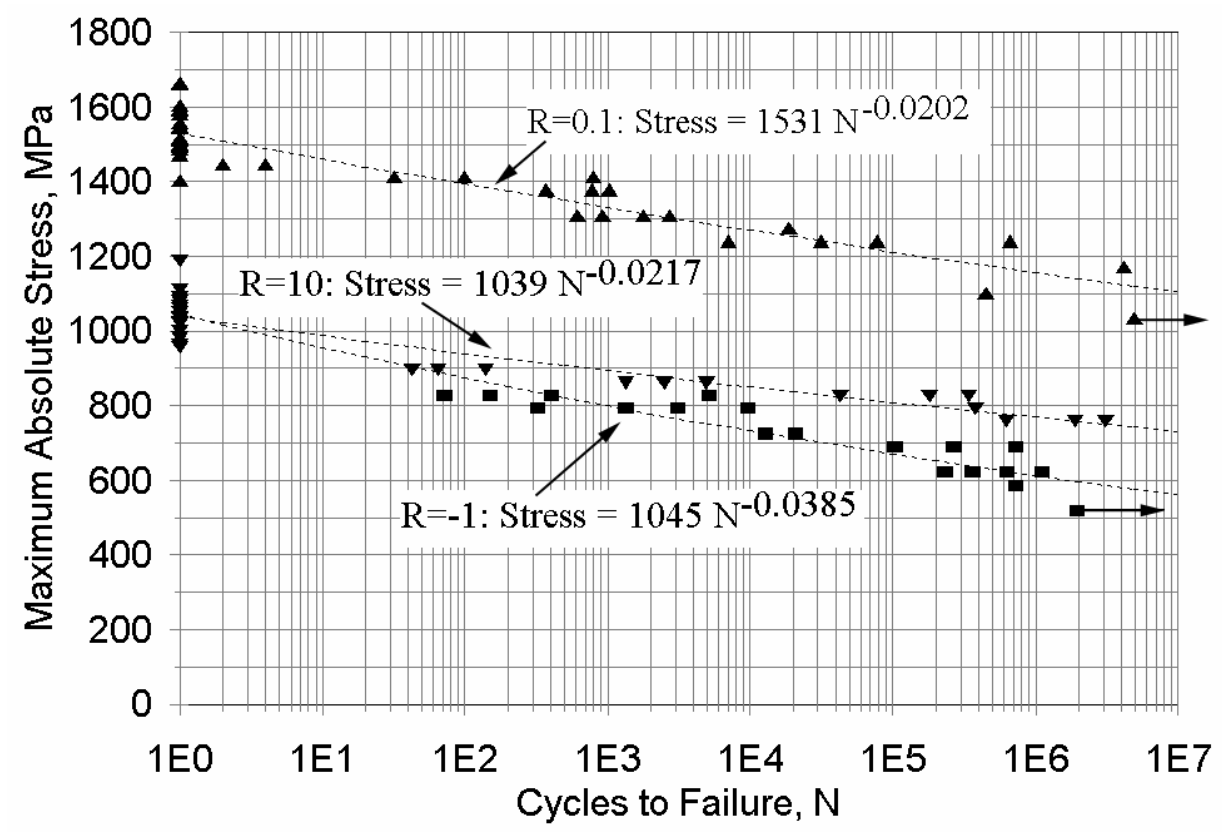

Figure 3. Maximum Absolute Stress to Failure Fatigue Data for $\left[ \pm \mathbf{4 5} / \mathbf{0}_{8} / \pm \mathbf{4 5}\right]$ Control Laminate, $R=0.1,10$ and -1 (No Ply Drops; $0^{\circ}$ plies are carbon, $\pm 45^{\circ}$ plies are glass).

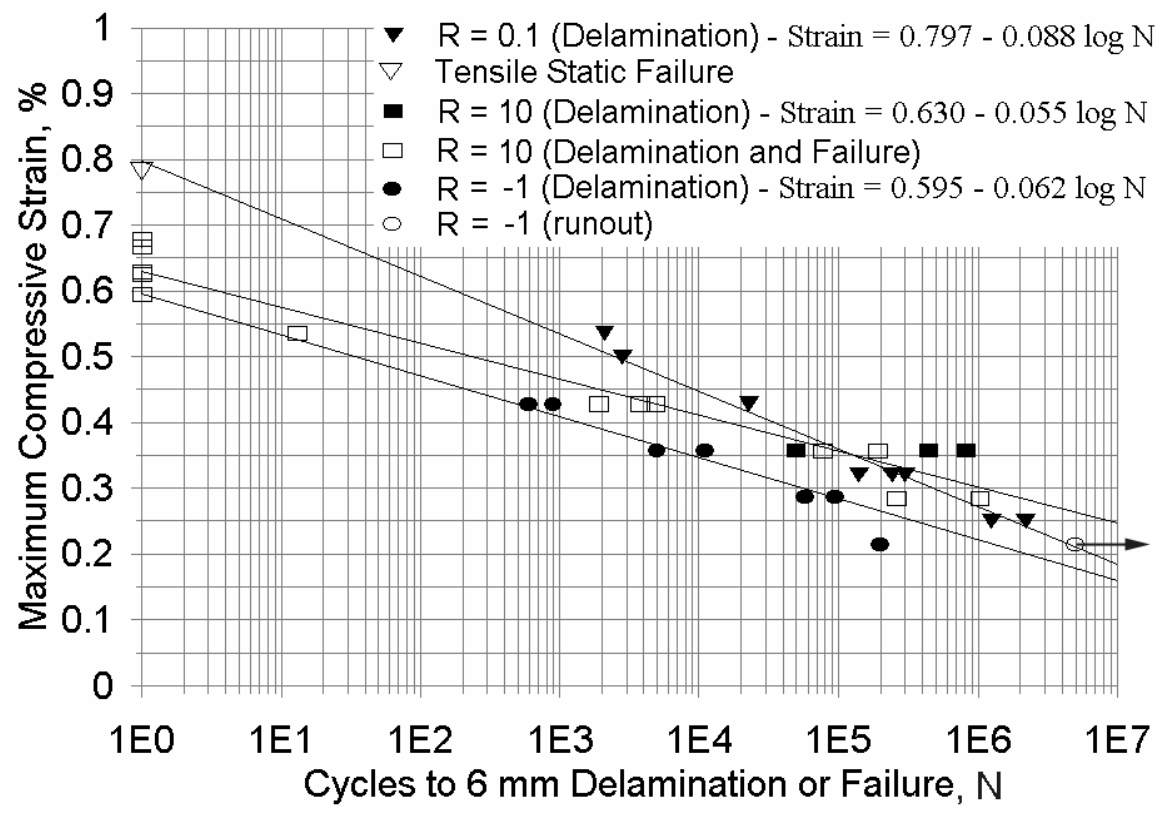

Figure 4. Maximum Absolute Strain versus Cycles to Failure and/or Delamination for Thin Laminates with Double Ply Drops $\left[ \pm 45 / 0_{2} * / 0_{9} / 0_{2} * / \pm 45\right], R=0.1,10$ and $-1\left(0^{\circ}\right.$ plies are carbon, $\pm 45^{\circ}$ plies are glass $)$. 


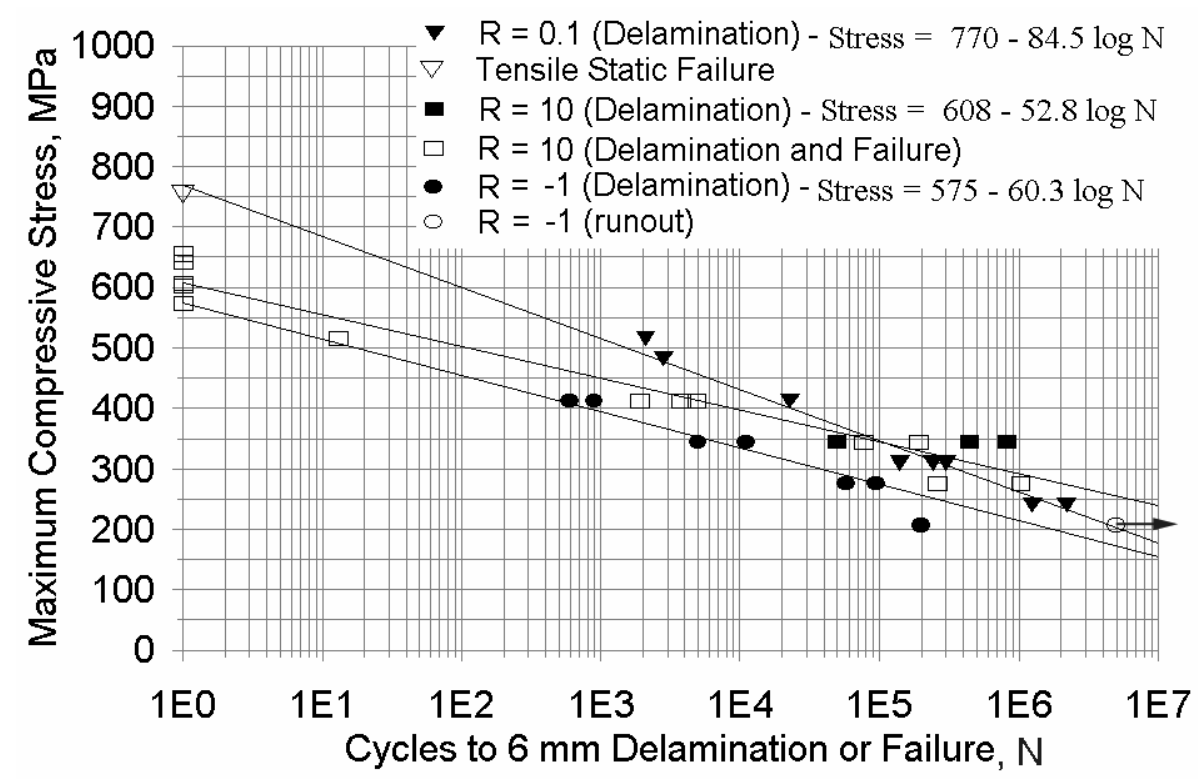

Figure 5. Maximum Absolute Stress versus Cycles to Failure and/or Delamination for Thin Laminates with Double Ply Drops $\left[ \pm 45 / 0_{2} * / 0_{9} / 0_{2} * / \pm 45\right], R=0.1,10$ and $-1\left(0^{\circ}\right.$ plies are carbon, $\pm 45^{\circ}$ plies are glass $)$.

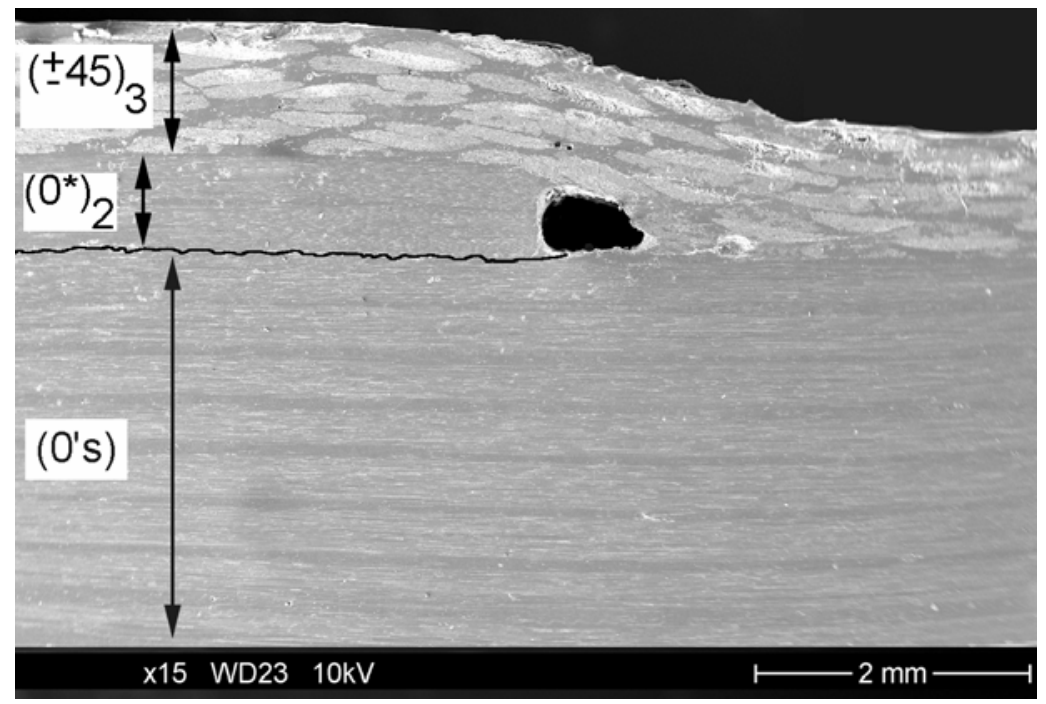

Figure 6. Photograph of Delamination Crack Growing from Pore Ahead of Double Ply Drop (See Fig. 1), Carbon $0^{\circ}$ Plies, Compression Fatigue (Crack Path Enhanced). 


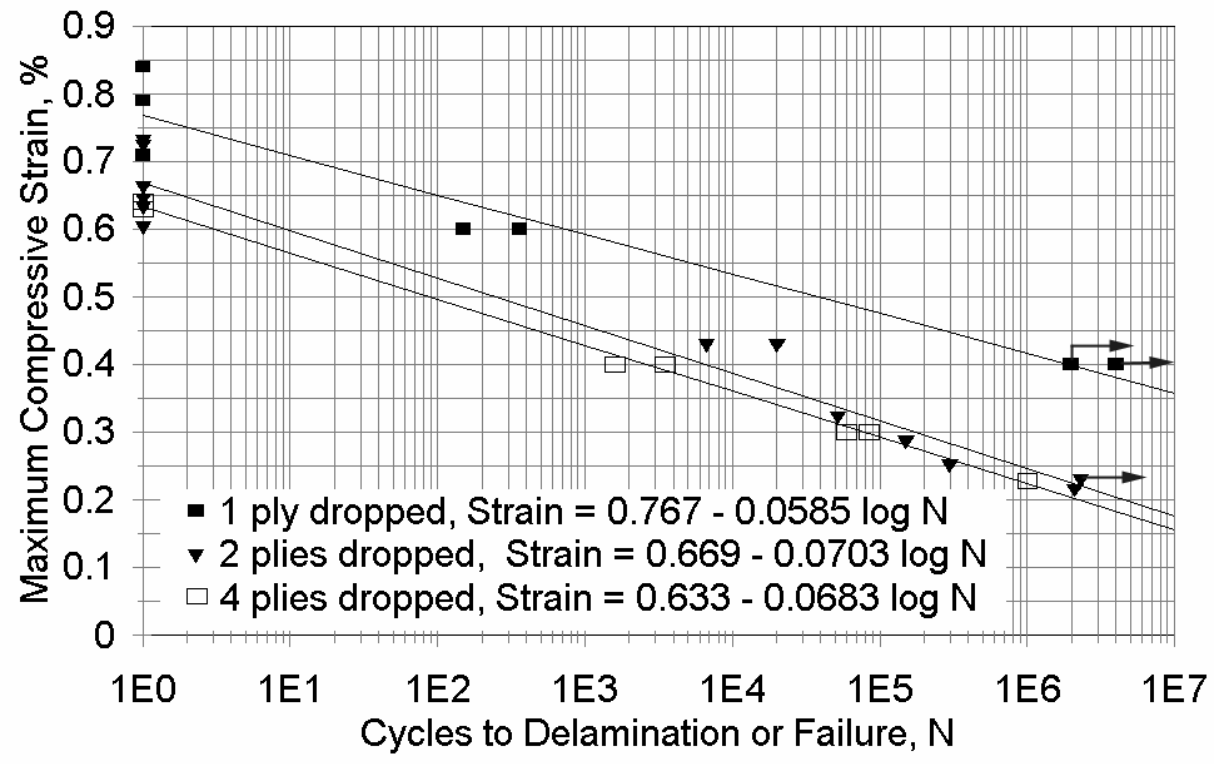

Figure 7. Strain-Cycles Results for a $\left[( \pm 45)_{3} / 0_{n} * / 0_{27} / 0_{n} * /( \pm 45)_{3}\right]$ Laminate with $n=1,2$, 4, Plies Dropped at the Surface of the $0^{\circ}$ Stack, $R=10\left(0^{\circ}\right.$ Plies are Carbon and $\pm 45^{\circ}$ Plies are Glass $)$.

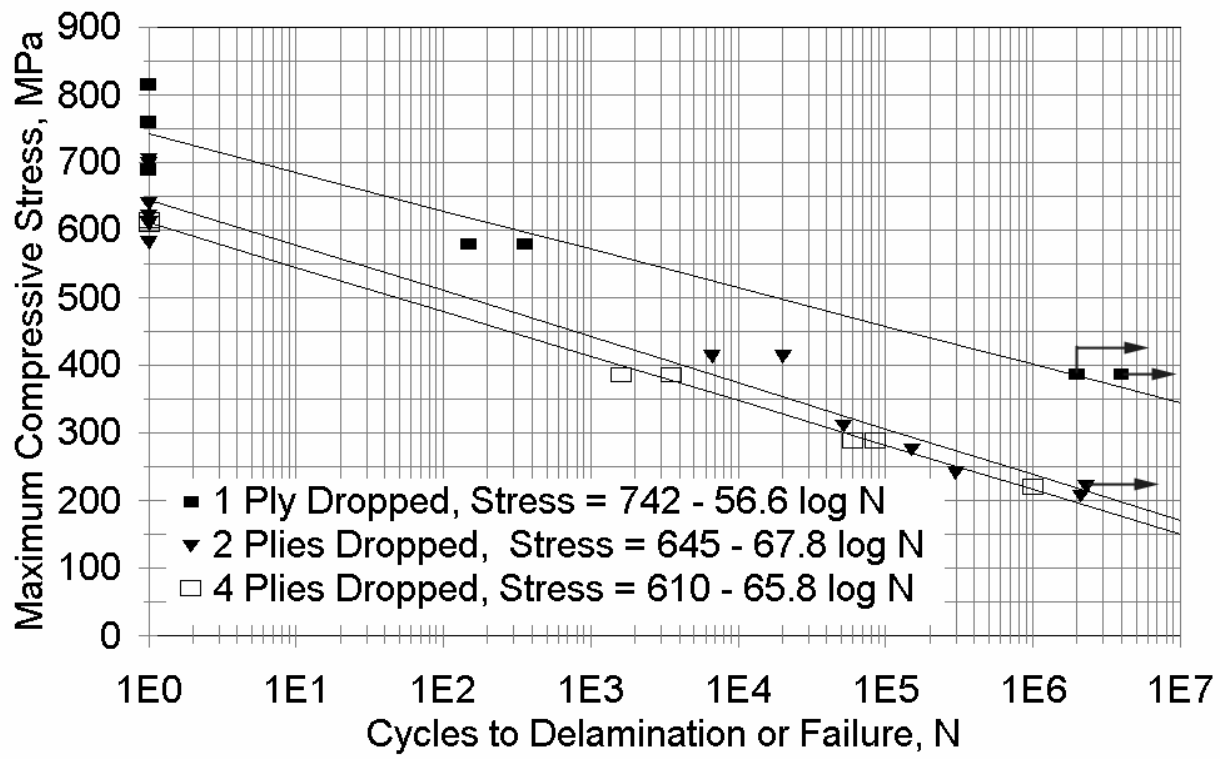

Figure 8. Stress-Cycles Results for a $\left[( \pm 45)_{3} / 0_{n} * / 0_{27} / 0_{n} * /( \pm 45)_{3}\right]$ Laminate with $n=1,2$ and 4 Plies Dropped at the Surface of the $0^{\circ}$ Stack, $R=10\left(0^{\circ}\right.$ Plies are Carbon and $\pm 45^{\circ}$ Plies are Glass). 


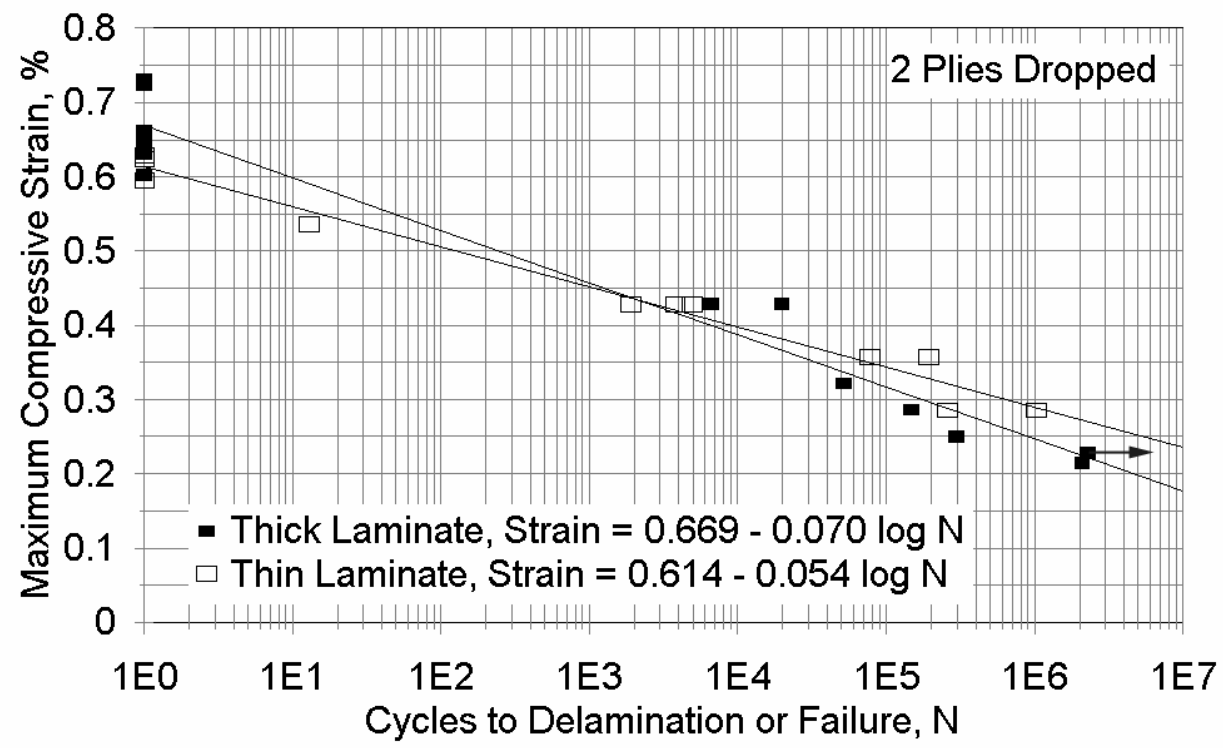

Figure 9. Comparison of Strain-Cycles Data for a Thick $\left[( \pm 45)_{3} / \mathbf{0}_{2} * / 0_{27} / \mathbf{0}_{2} * /( \pm 45)_{3}\right]$ Laminate and a Thin $\left[ \pm 45 / 0_{2} * / 0_{9} / 0_{2}{ }^{*} \pm 45\right]$ Laminate, Double Surface Ply Drops $\left(0^{\circ}\right.$ Plies are Carbon and $\pm 45^{\circ}$ Plies are Glass).

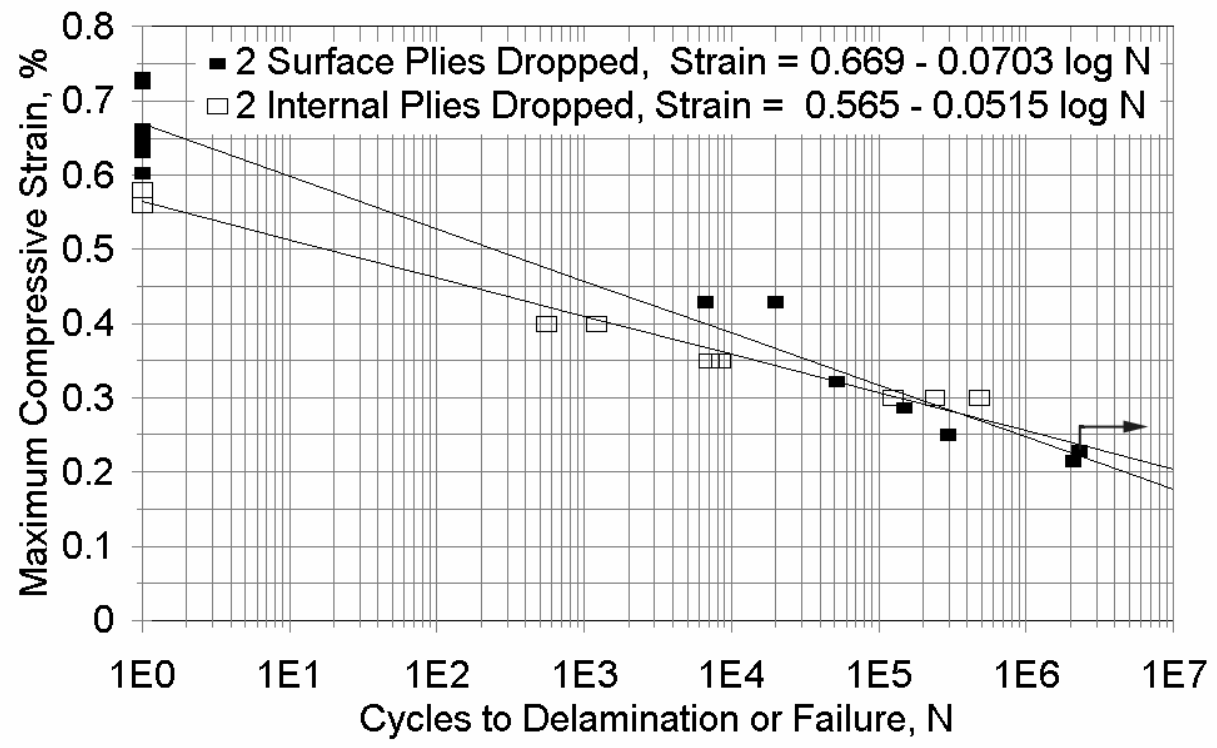

Figure 10. Comparison of Strain-Cycles Data for Surface $\left[( \pm 45)_{3} / \mathbf{0}_{2} * / \mathbf{0}_{27} / \mathbf{0}_{2} * /( \pm 45)_{3}\right]$ and Internal $\left[( \pm 45)_{3} / \mathbf{0}_{9} / \mathbf{0}_{2} * / 0_{9} / 0_{2} * / 0_{9} /( \pm 45)_{3}\right]$ Double Ply Drops, $R=10\left(0^{\circ}\right.$ Plies are Carbon and $\pm 45^{\circ}$ Plies are Glass $)$. 


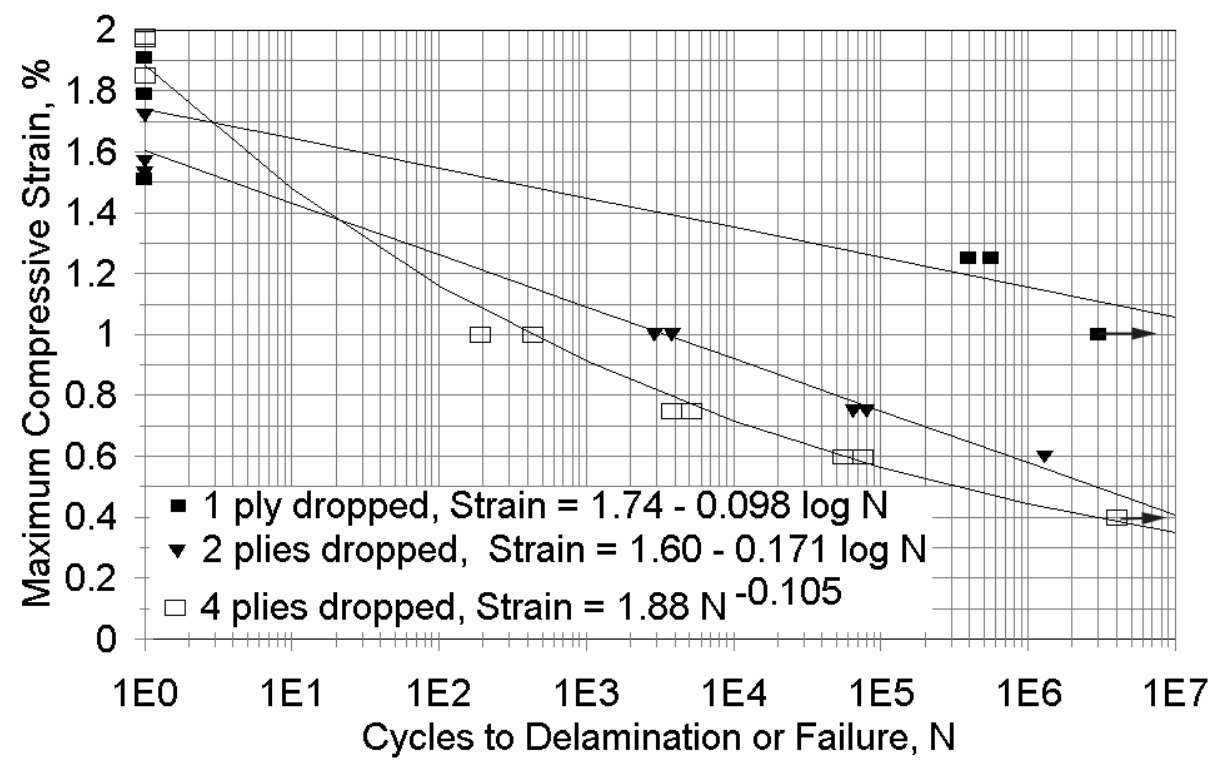

Figure 11. Strain-Cycles Results for an All-Fiberglass Laminate $\left[( \pm 45)_{3} / 0_{n} * / 0_{27} / 0_{n} * /( \pm 45)_{3}\right]$ with $n=1,2$ and 4 Plies Dropped at the Surface of the $0^{\circ}$ Stack, $R=10\left(0^{\circ}\right.$ and $\pm 45^{\circ}$ Plies are Glass).

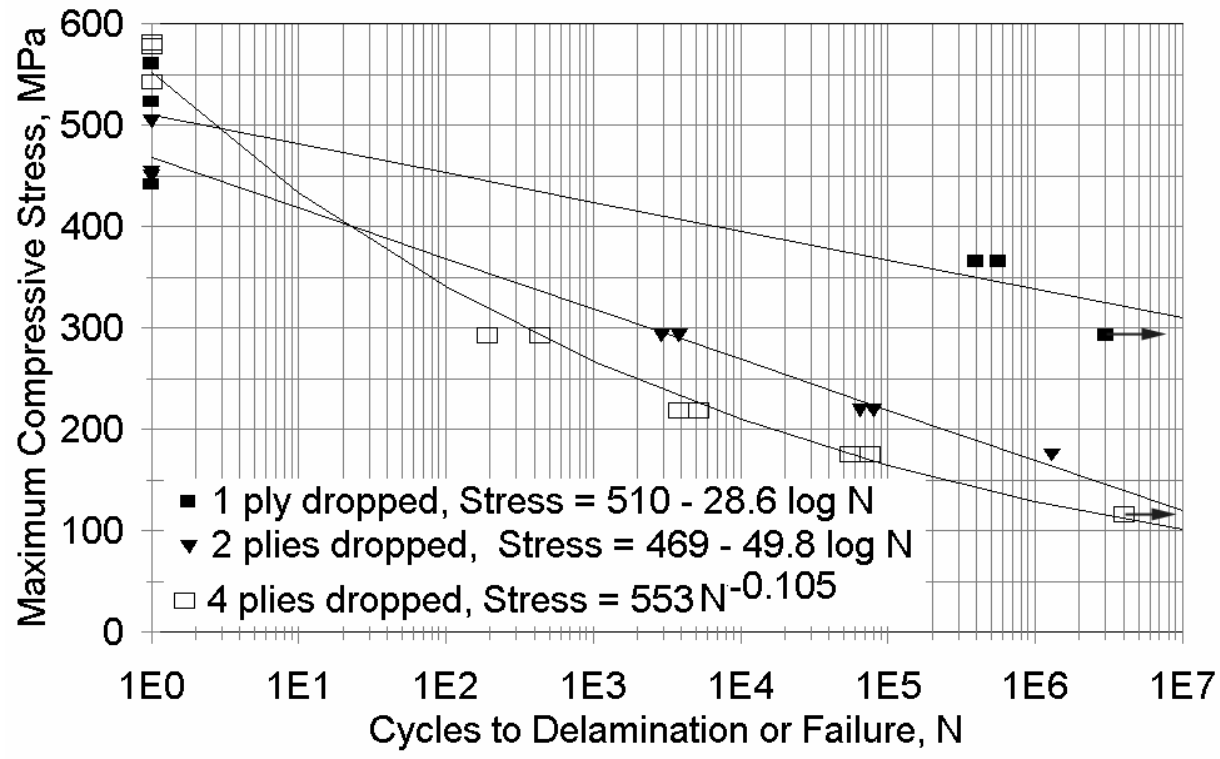

Figure 12. Stress-Cycles Results for an All-Fiberglass Laminate $\left[( \pm 45)_{3} / 0_{n} * / 0_{27} / 0_{n} * /( \pm 45)_{3}\right]$ with $n=1,2$ and 4 Plies Dropped at the Surface of the $0^{\circ}$ Stack, $R=10\left(0^{\circ}\right.$ and $\pm 45^{\circ}$ Plies are Glass $)$. 


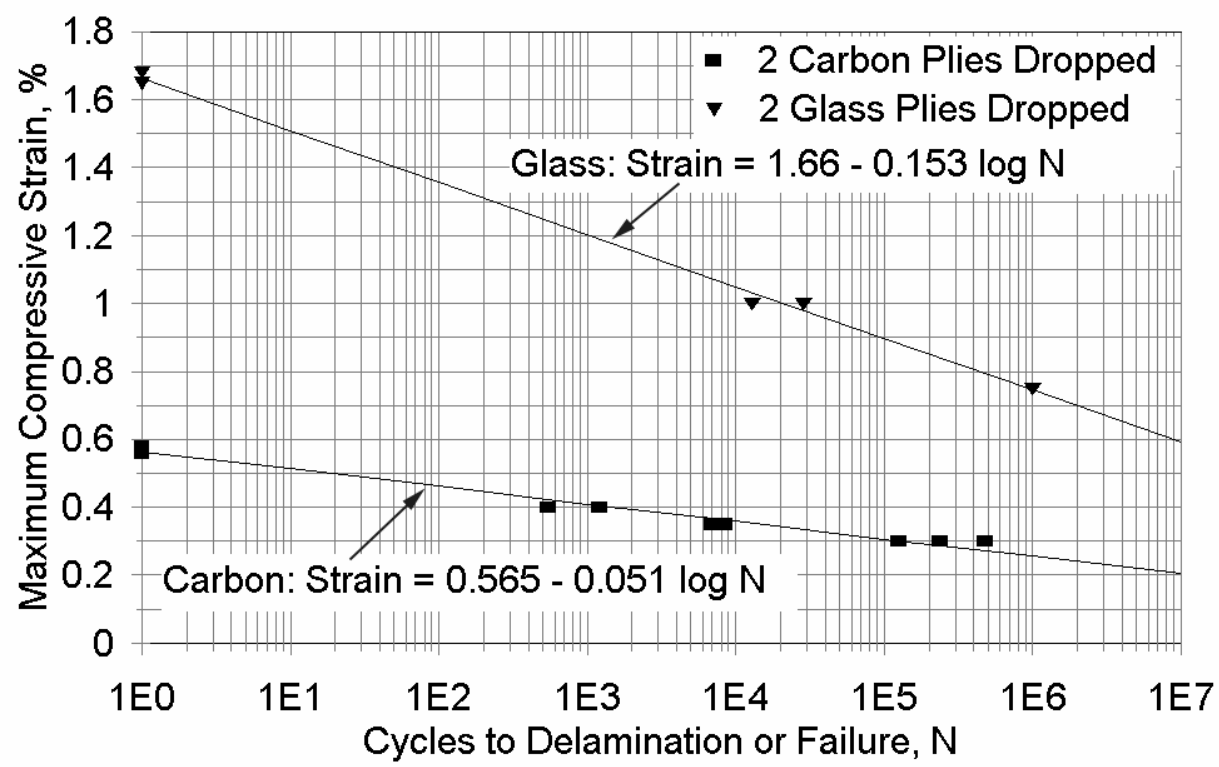

Figure 13. Strain-Cycles Comparison for Laminates with Carbon vs. Glass $0^{\circ}$ Plies, Double Interior Ply Drops $\left[( \pm 45)_{3} / 0_{9} / 0_{2} * / 0_{9} / 0_{2} * / 0_{9} /( \pm 45)_{3}\right]( \pm 45$ Plies are Glass $)$.

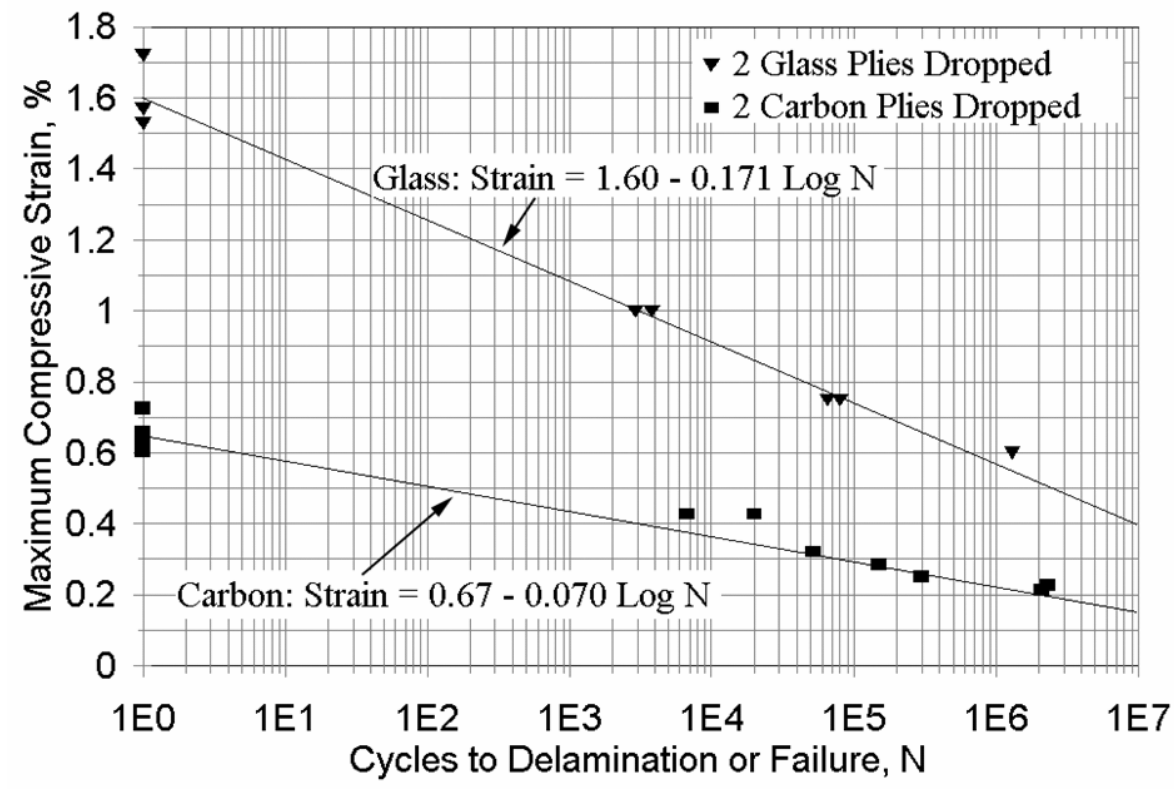

Figure 14. Strain-Cycles Comparison for Laminates with Carbon vs. Glass $0^{\circ}$ Plies, Double Exterior Ply Drops $\left[( \pm 45)_{3} / \mathbf{0}_{2} * / 0_{27} / \mathbf{0}_{2} * /( \pm 45)_{3}\right]( \pm 45$ Plies are Glass $)$. 


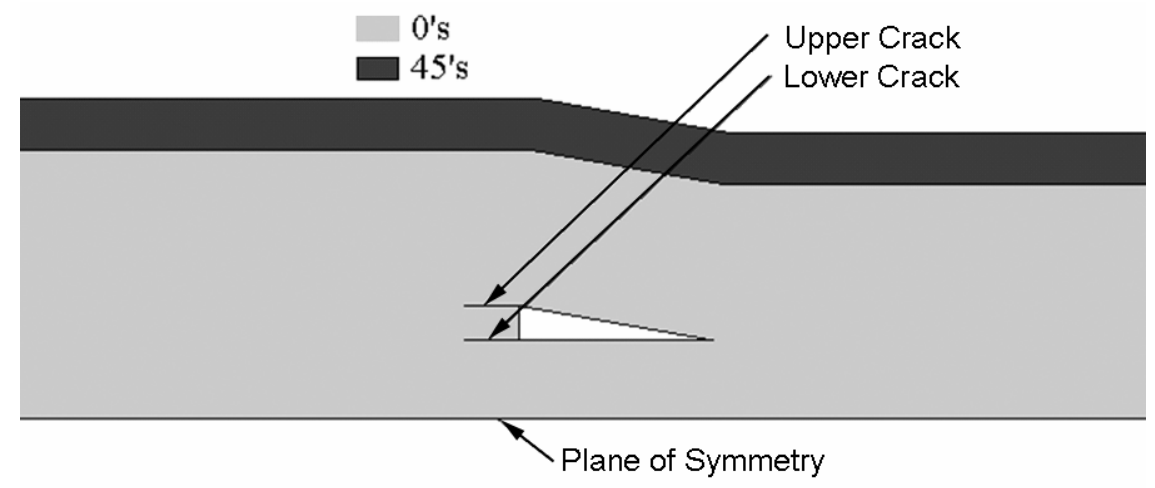

Figure 15. Finite Element Model Showing Internal Ply Drop, Delamination Cracks and Pore Ahead of Ply Drop.

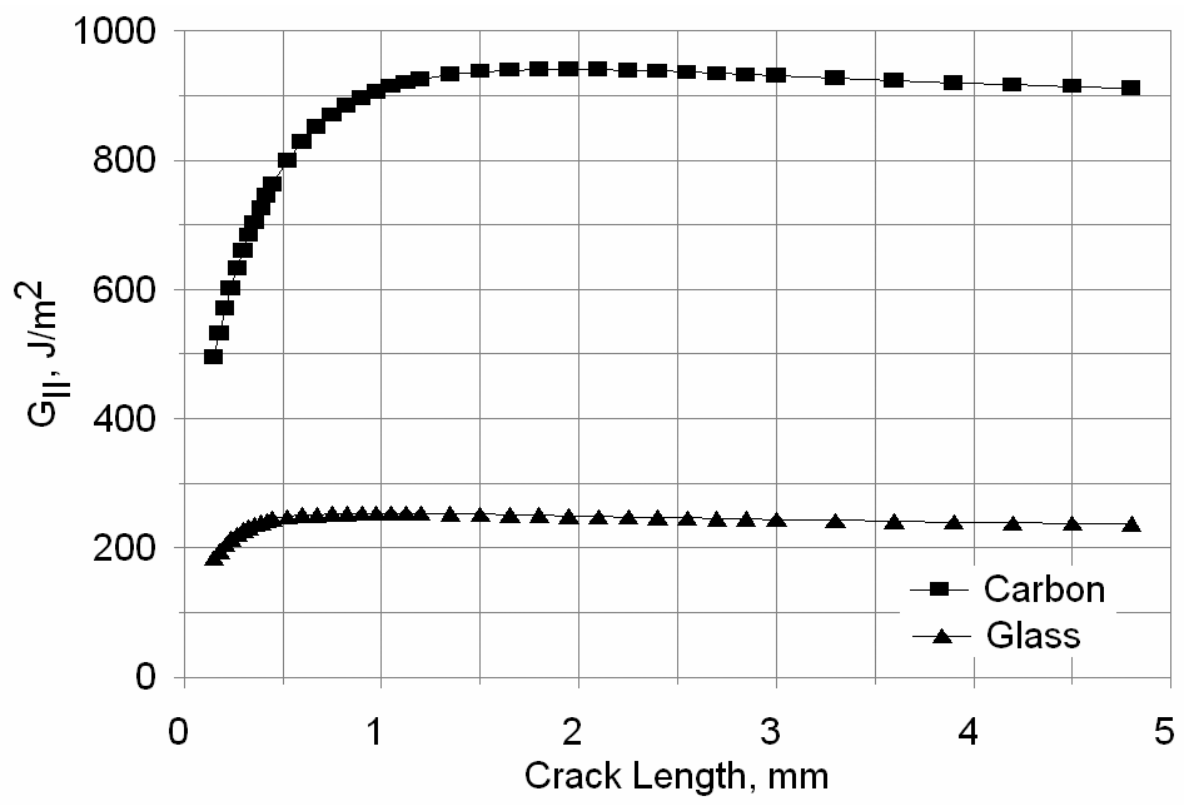

Figure 16. Comparison of Glass and Carbon FEA Results for Internal Ply Drop under Tensile Load, Total $\mathrm{G}_{\mathrm{II}}$ Component for both Cracks $\left(\mathrm{G}_{\mathrm{I}} \approx 0\right)$, Thin Side Strain $=0.5 \%$. 


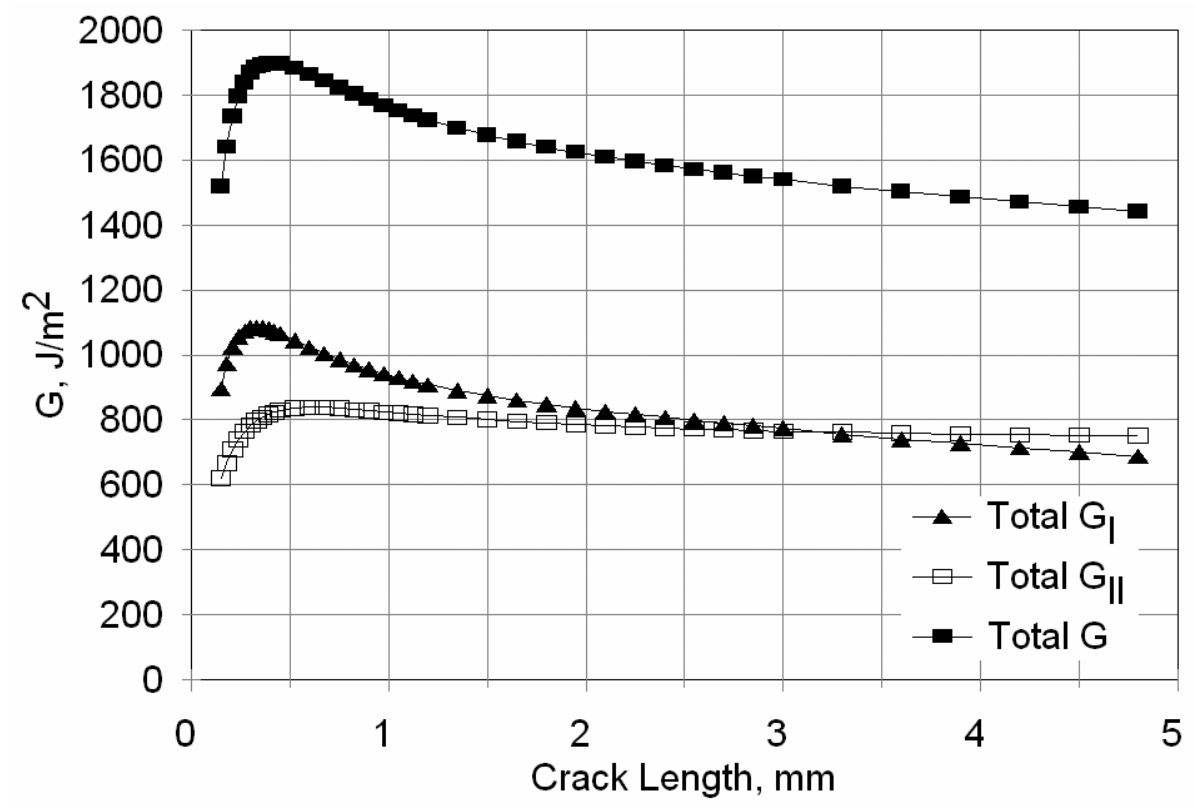

Figure 17. Same FEA Case as Figure 16, but Compression Load (Same Strain), Carbon $0^{\circ}$ Plies. 